\title{
Os princípios do cooperativismo e 0 trabalho em equipe em cooperativas de Garibaldi-RS
}

\section{RESUMO}

O objetivo deste artigo é verificar se as cooperativas de Garibaldi seguem os princípios do cooperativismo. Para atingir esse objetivo, buscou-se conhecer o histórico de desenvolvimento das cooperativas do Estado do Rio Grande do Sul, dimensionar os benefícios e as dificuldades relacionados ao trabalho em equipe em cooperativas e conhecer os aspectos relacionados ao trabalho dos líderes nas organizações cooperativadas. A pesquisa de campo ocorreu em cooperativas de Garibaldi, e para tanto, foi realizado um estudo de natureza qualitativa, onde as informações foram obtidas com os líderes das cooperativas analisadas. A técnica de pesquisa utilizada foi a entrevista semiestruturada, por meio de um roteiro prévio de entrevista, e análise bibliográfica sobre o tema. Após interpretação e análise das informações coletadas, pôde-se verificar que as cooperativas em estudo seguem os princípios do cooperativismo e que o trabalho em equipe é de grande importância para elas, pois melhora o desempenho dos integrantes da equipe, beneficia cooperados e clientes, e ainda aprimora os resultados da organização.

Palavras-chave: Cooperativismo. Trabalho em equipe. Integração.

Dalvana Piletti

dalpiletti@gmail.com

Administradora da Faculdade de Integração do Ensino Superior do Cone Sul (FISUL)

Gustavo da Rosa Borges gustavodarosaborges@gmail.com

Mestre em Administração - Universidade do Vale do Rio dos Sinos (UNISINUS) Doutorando em Administração - Fundação Universidade Regional de Blumenau(FURB)

Isabel Cristina Rosa Barros Doutoranda em Administração - Universidade Caxias do Sul (UCS) Universidade Federal de Pelotas (UFPel) 


\section{INTRODUÇÃO}

As empresas estão cada vez mais conscientes da importância das equipes de trabalho e buscam, com isso, tornar um ambiente de trabalho salutar e produtivo. De acordo com Senge (2006), as pessoas que integram uma equipe devem ter um objetivo comum, unindo-se para alcançar os resultados desejados. Muitas vezes, as empresas optam por treinamentos para desenvolver as equipes que, segundo Pinheiro e Reginato (2003), trata-se de uma prática que permite a melhora das atitudes das pessoas e desenvolve suas habilidades, fazendo com que haja eficácia na resolução de problemas, boa comunicação, melhor comprometimento e qualidade de vida dos colaboradores (BEJARANO; PILATTI, 2008).

Uma das formas em que as empresas vêm há tempos buscando gerenciar os seus recursos humanos é adotando uma postura de suporte às equipes de trabalho. Vergara (2012) destaca algumas vantagens no trabalho em equipe, dentre elas, a agilidade na captação e uso das informações, o surgimento de ideias de melhor qualidade em virtude de diferentes visões do tema estudado, o aumento na tendência em assumir riscos, pois a responsabilidade é compartilhada e, por fim, o comprometimento de todos os membros da equipe que se sentem responsáveis pelo resultado obtido. Portanto, seguir os princípios do cooperativismo torna-se relevante para que as cooperativas continuem desenvolvendo-se. Para tanto, elas podem desenvolver equipes qualificadas, unindo-se em busca de objetivos comuns, gerando empregos e renda e beneficiando a sociedade.

Neste artigo, pesquisaram-se bibliograficamente, conceitos de equipe e aprendizagem adquirida, e empiricamente, a percepção de líderes de duas equipes de trabalhos de duas Cooperativas de Garibaldi-RS. A abordagem empírica buscou destacar a comunicação, a motivação, o comprometimento, a liderança e os conflitos que podem surgir entre os seus membros. Dessa forma, os princípios do cooperativismo e o trabalho em equipe nas organizações cooperativadas são de grande importância, pois motivam e valorizam as pessoas fazendo com que estas executem suas tarefas com eficácia. Assim, o estudo a ser realizado nas cooperativas indicará os benefícios e as dificuldades das equipes de trabalho no dia a dia, nessas organizações. Isso se aplica a maioria das organizações, inclusive nas cooperativadas, que devem demonstrar resultados perante os seus associados e clientes, trabalhando da melhor maneira possível, organizando e controlando suas ações de modo a satisfazer as partes interessadas, inclusive as equipes de trabalho.

O problema de pesquisa é: as cooperativas de Garibaldi seguem os princípios do cooperativismo? Seguindo essa linha de questionamento, este trabalho tem por objetivos verificar se as cooperativas de Garibaldi seguem os princípios do cooperativismo, conhecer os aspectos relacionados ao trabalho dos líderes e contribuir para o desenvolvimento das cooperativas.

Para alcançar os objetivos propostos, este trabalho buscará conhecer brevemente o histórico de desenvolvimento das cooperativas no estado do Rio Grande do Sul, dimensionar os benefícios e as dificuldades relacionados ao trabalho em equipe e conhecer os aspectos relacionados ao trabalho de líderes nas duas organizações cooperativadas pesquisadas. Com isso, chegar ao objetivo principal de verificar se as cooperativas de Garibaldi seguem os princípios do cooperativismo.

O presente estudo pretende ajudar aos gestores a apoiar e auxiliar as equipes de trabalho, podendo resultar em um melhor desempenho e melhorar os resultados obtidos. Em termos científicos, pretende-se contribuir para uma maior compreensão de um tema ainda pouco explorado em trabalhos teórico-empíricos.

\section{REFERENCIAL TEÓRICO}

O referencial teórico será dividido em: origens do cooperativismo, cooperativismo no Brasil, cooperativismo no Rio Grande do Sul e trabalho em equipe.

\subsection{Origens do cooperativismo}

Por meio da cooperação, a humanidade sobreviveu desde o princípio até hoje, protegendo-se de animais ferozes e adversidades do clima, solucionando problemas como a fome e a doença, entre outros aspectos. De acordo com Simon (2011), no decorrer da história humana, as pessoas ajudaram-se mutuamente. Com 
o desenvolvimento das sociedades, especialmente com a Revolução Industrial na Inglaterra, França e Alemanha, aumentou a exploração dos trabalhadores pelos proprietários das indústrias. Esses trabalhadores trabalhavam 17 horas por dia e recebiam pouco, sendo o cooperativismo uma das reações deles perante essa situação. Figueiredo (2009) afirma que fábricas, principalmente de tecidos, eram piores do que prisões, já que ofereciam ambientes insalubres aos trabalhadores. Figueiredo (2009) também relata que o cooperativismo surgiu como esperança para essas pessoas que viviam em situações tão precárias, por meio da união, terem uma melhor situação de vida.

Cooperar é unir-se a outras pessoas para enfrentar juntas situações adversas, transformando-as em oportunidades e situações de bem-estar econômico e social. Cooperativismo é um movimento internacional cujo objetivo é libertar o homem do seu individualismo por meio da cooperação entre as pessoas. Cooperativa é a organização de pelo menos vinte pessoas físicas, unidas pela cooperação com objetivos econômicos e sociais comuns. Associado ou cooperado é a pessoa que, sendo sócio de uma cooperativa, dela recebe as vantagens advindas da cooperação de todos os associados (FIGUEIREDO, 2009).

Na concepção de Schneider (2012), foi no século XIX que surgiram condições favoráveis para o cooperativismo na Europa, visando corrigir e reformar a economia, norteando a ação dos homens. Isso se deu por intermédio do avanço do liberalismo econômico e pela importância da razão e da liberdade. As cooperativas começaram a proliferar pela influência de pensadores como Owen, William King, Buchez, Charles Gide e outros que procuravam uma organização social mais justa e equitativa (SCHNEIDER, 2012). Nesse contexto, Figueiredo (2009) argumenta que esses visionários foram chamados por Karl Marx de socialistas utópicos, pois pretendiam transferir para os operários poderes financeiros, por aconselhar a justiça e a fraternidade nas relações econômicas e sociais.

Zeni (2008) explica que o avanço técnico e científico foi o marco da revolução industrial, surgindo formas novas de executar a atividade laboral. Segundo o autor, com a falta de oportunidade e novos postos de trabalho surgiu a organização do cooperativismo.

A ideia e o espírito de cooperação sempre estiveram presentes ao longo de toda a evolução humana. $O$ cooperativismo possui uma origem histórica muito além dos Pioneiros de Rochdale.

Em Rochfale, na Inglaterra, por volta de 1845, ocorreu a primeira experiência organizada de cooperativismo. Foram definidos estatutos e os valores atribuídos a essa pioneira formação de trabalhadores. A nova formação trabalhista teve como objetivo principal uma oposição a um modelo de gestão impositivo. O pioneirismo ocorrido na Inglaterra contribui mais adiante, para alavancar o cooperativismo em outros diversos países (SINGER, 2002).

Entretanto, existem relatos de trabalhos organizados análogos às cooperativas entre os Astecas e Incas (na agricultura), babilônios e palestinos. No século IV a.C., na Babilônia, existia um sistema organizado de trabalho desenvolvido coletivamente em terras arrendadas. Mais adiante, no século III a. C., na República de Platão, onde o espírito comunitário e associativo sugeria a divisão das terras entre todos, escravos, crianças e apesar da absurda discriminação que a mulher sofria, inclusive esta, também teria direito à partilha das terras. Já em Roma, no século II a. C., difundiam-se as "Escolas Cooperativas", que ensinavam profissões, como sapateiros, ferreiros, carpinteiros, além de outras atividades. Tudo isso acontecia com a ajuda recíproca entre os frequentadores das referidas Escolas (ZENI, 2008).

Figueiredo (2009) explica que, no final de 1843, na Inglaterra, em Manchester, no bairro de Rochdale, várias pessoas reuniram-se, pois estavam passando por dificuldades e cansadas de serem exploradas. Com a finalidade de melhorar a vida de seus membros, economizaram o capital de uma libra esterlina por ação, com o objetivo de fundar um armazém cooperativo. Criaram um estatuto com normas econômicas e sociais e, em 21 de dezembro de 1844, os 28 tecelões já possuíam um capital de 28 libras esterlinas. Primeiramente, montaram um armazém e, posteriormente, apoiaram a construção de casas para os tecelões.

Em 21 de dezembro de 1844, um grupo de 28 pessoas, na cidade de Rochdale, na Inglaterra, num lugar chamado Toad-Lane (Beco do Sapo) lançaram-se as bases da primeira cooperativa de tecelões, denominada de Sociedade dos Probos Pioneiros de Rochdale. Ao final do primeiro ano, a cooperativa contava com 74 sócios. Depois de 11 anos, já possuía 400, e 22 anos depois, alcançava seis mil. Estava lançada a semente do cooperativismo mundial que hoje conta com mais de 900 milhões de associados (SIMON, 2011). Schneider (2012) diz que as regras sistematizadas pelos tecelões foram fundamentais para o funcionamento das cooperativas, como: (a) 
gestão democrática pelos membros; (b) participação econômica dos membros; (c) autonomia e independência; (d) educação, formação e informação; (e) inter cooperação; (f) compromisso com a comunidade.

A origem do cooperativismo foi de grande significado, as pessoas descobriram a força da união e a importância da ajuda mútua. Com os passar dos anos, sentiram a necessidade da busca por conhecimento, possibilitando assim o desenvolvimento das cooperativas.

\subsection{Cooperativismo no Brasil}

Em 1610, foram fundadas as primeiras reduções jesuíticas no Brasil, onde se iniciou uma espécie de estado cooperativo em bases integrais. Por mais de 150 anos, esse modelo foi exemplo de sociedade solidária, com base no trabalho coletivo, onde o bem-estar do indivíduo e da família era mais importante do que o interesse econômico da produção. Essa ação foi movida pelos padres jesuítas que catequizaram os indígenas brasileiros (COOPESP, 2012).

Conforme Figueiredo (2009), o primeiro registro de uma cooperativa brasileira é de 1889, uma cooperativa de consumo em Minas Gerais, nominada Sociedade Cooperativa Econômica dos Funcionários Públicos de Ouro Preto. Em 1891, surge a Associação Cooperativista dos Empregados da Companhia Telefônica de Limeira/ SP. Em 1892, foi criada a "Societa Cooperativa DelleConvenzioniAgricoli", uma cooperativa de produtores rurais em Veranópolis e Antonio Prado, no Rio Grande do Sul. Em 1894, nasce a Cooperativa Militar de Consumo, no Rio de Janeiro. Em 1895, a Cooperativa de Consumo de Camaragipe/PE. Em 1902, foi criada a primeira Caixa Rural Cooperativa do Brasil e da America Latina, uma cooperativa de crédito em Nova Petrópolis/RS, chamada hoje de Sicredi Pioneira. Sua criação proporciona ao Rio Grande do Sul o título nacional de "Berço do Cooperativismo Brasileiro" (FIGUEIREDO, 2009).

As primeiras cooperativas no Brasil foram de consumo. Em 1887, surge a Cooperativa de Consumo dos Empregados da Companhia Paulista, em Campinas/SP. Em 1889, em Ouro Preto/MG, foi criada uma Sociedade Econômica Cooperativa. Em 1891, em Limeira/SP, foi fundada a Cooperativa dos Empregados da Companhia Telefônica. No Rio de Janeiro surgiu a Cooperativa Militar de Consumo no ano de 1894. Em 1895, foi constituída a Cooperativa de Consumo de Camaragibe, em Pernambuco. Em 1913, surgiu a Cooperativa dos Empregados e Operários da Fábrica de Tecidos da Gávea e a Cooperativa de Consumo Operária do Arsenal de Guerra, no Rio de Janeiro. No mesmo ano, em Santa Maria/RS, foi fundada a Cooperativa de Consumo dos Empregados da Viação Férrea (COOPESP, 2012).

Em 1907, em Minas Gerais surgem as primeiras cooperativas agropecuárias. O governador do estado, João Pinheiro, lançou seu projeto cooperativista com o objetivo de eliminar os intermediários da produção agrícola, sendo o café sua principal preocupação, criou uma seção para isenção fiscal e estímulo material para o produto. Essas cooperativas dividem-se conforme os tipos dos produtos com os quais trabalham. A maioria tem mais de uma seção: a de compras em comum (para compra de insumos, adubos, sementes, instrumentos, etc.) e a de vendas em comum (venda dos produtos dos cooperados) (COOPESP, 2012).

\subsection{Cooperativismo no Rio Grande do Sul}

De acordo com Zeni (2008), a partir do século XVII, o Sul do Brasil demonstrou o espírito cooperativista por meio das Missões Jesuítas em 1610, quando os padres jesuítas vieram catequizar os índios. Mas, somente em 1847, foi difundido o movimento cooperativista no país, quando Jean Maurice Faivre, médico francês, fundou a Colônia Tereza Cristina (Paraná), organizada em bases cooperativas.

Willwock et al. (2014) destacam que, conforme a diocese de Pelotas, o cooperativismo no Rio Grande do Sul começou por volta do século XVII, em 1626, quando o Padre Roque Gonzales, de Santa Cruz, atravessou o rio Uruguai para iniciar os primeiros aldeamentos dos índios guaranis. Assim, foi fundado o município São Nicolau. Devido a resistências locais, esse movimento foi interrompido e retomado somente em 1682, com as reduções guaraníticas. Nesse período, o gado que o Pe. Cristóvão de Mendonza trouxe havia se reproduzido extraordinariamente, sendo base da alimentação dos povos indígenas. Entretanto, em 1750, por intermédio do Tratado de Madrid, Espanha e Portugal resolvem trocar a Colônia do Sacramento por Sete Povos das Missões, 
com o obrigatório abandono das terras e casas por parte de todos os índios do lado leste do rio Uruguai. Os missioneiros rebelaram-se e ofereceram resistência. As duas coroas uniram-se e na Guerra Guaranítica (17541756) dizimaram os agricultores guaranis. Dessa forma, a experiência da Província Jesuítica do Paraguai foi interrompida com a expulsão dos padres da Companhia de Jesus em 1759. Bem mais tarde, uma nova onda de organização social ocorreu pela chegada de um novo jesuíta no Rio Grande do Sul. Foi por meio da fundação da Primeira Associação de Agricultores em 1900, em Santa Catarina da Feliz, que o Pe. Theodor Amstad ajuda a fundar a Primeira Cooperativa de Crédito do Brasil, em 1902, no município de Nova Petrópolis, na Linha Imperial (WILLWOCK et al., 2014).

Segundo Lago e Silva (2009), como exemplo de riqueza e a variedade de uma experiência associativa, há as referências de cooperação econômica e social, desenvolvidas no período das Reduções Jesuíticas em uma área importante do Rio Grande do Sul que foi bruscamente eliminada com uma decisão político-militar das coroas da Espanha e de Portugal, coincidindo com a expulsão dos jesuítas.

Segundo Willwock et al. (2014), em 1892 Vicente Monteggia fundou em Antonio Prado a primeira cooperativa dos produtores rurais. Em 1894, um grupo de imigrantes italianos cria a primeira cooperativa de produção artesanal em Caxias do Sul. Em 1902, um novo jesuíta chega ao Rio Grande do Sul, Pe. Theodor Amstad, que ajuda a fundar a primeira cooperativa de crédito do Brasil, no município de Nova Petrópolis. Em 1911, Giuseppe Stéfano Paternó foi contratado pelo governo e fundou dezesseis cooperativas na região da Serra, em 1913 Paternó retorna à Itália e observa-se que poucas cooperativas fundadas por ele tiveram sucesso. Em 1929, surge a primeira cooperativa de vitivinicultores na Serra. Em 1938, o Rio Grande do Sul já possuía 279 cooperativas.

Para Viana (2013) existem 43 cooperativas educacionais no Estado gaúcho e destaca a primeira cooperativa do ramo: A Cooperativa Educacional de Ensino Básico (COOPEEB), fundada no Rio Grande do Sul em 9 de maio de 2000, conforme registrado pela Organização das Cooperativas do Estado do Rio Grande do Sul (OCERGS).

Segundo estudo da OCB/Sescoop, divulgado em 2011, houve um aumento de $4 \%$ de cooperados, correspondendo a 370 mil novas adesões no ano. $\mathrm{O}$ estudo ainda divulga o número de associados por Estado, existem 3,4 milhões de cooperativados em São Paulo, 2,1 milhões no Rio Grande do Sul e 1,2 milhão em Santa Catarina, sendo estes os Estados com maior número de cooperativados (OCB, 2015).

\subsection{Trabalho em equipe}

Figueiredo (2009) destaca o trabalho em equipe como uma das virtudes do cooperativismo. Com base nesse ponto passa-se a estudar equipes de trabalho nas organizações. Oliveira (2011) explica que trabalho é uma atividade que requer energia física e mental; e equipe é um conjunto de pessoas que se empenham na realização desse trabalho. Esses são conceitos básicos que definem trabalho em equipe e são confirmados por Vergara (2012, p. 190):

um conjunto de pessoas trabalhando juntas é apenas um conjunto de pessoas. Para que se torne uma equipe é preciso que haja um elemento de identidade, elemento de natureza simbólica, que una as pessoas, estando elas fisicamente próximas, ou não.

Um grupo é transformado em uma equipe quando "as pessoas estão comprometidas com uma missão e objetivos comuns; cooperam mutuamente nas ações que requerem habilidades gerais e também específicas, havendo uma forte relação de confiança e parceria" (MACÊDO et al., 2006, p. 129). Senge (2006) ressalta que os membros da equipe devem focar suas energias para a mesma direção, com um objetivo comum e visão compartilhada, assim sendo, um complementa o esforço do outro. Uma equipe alinhada é fundamental para o alcance de resultados.

De acordo com Reis et al. (2006, p. 65), "equipes são conjuntos de indivíduos reunidos com o propósito de gerar sinergia que leve a resultados melhores do que os obtidos por meio da soma de resultados individuais".

Os mesmos autores complementam salientando que, 
para manter diferencial competitivo, a organização precisará descobrir como obter a adesão das pessoas e fazer com que se disponham a aprender e a mudar conforme as exigências do contexto. Nenhuma equipe de trabalho nasce pronta; ela aprende e se desenvolve continuamente (REIS et al., 2006, p. 66).

Senge (2006) explica a importância da visão compartilhada e do domínio pessoal desde que os membros das equipes aprendam juntos constantemente. A aprendizagem em equipe é o processo de alinhamento e desenvolvimento da capacidade da equipe de criar os resultados que seus membros realmente desejam. Ela baseia-se na disciplina do desenvolvimento da visão compartilhada. Também se fundamenta no domínio pessoal, pois as equipes talentosas são compostas de indivíduos talentosos. No entanto, visão compartilhada e talento não bastam. $\mathrm{O}$ mundo está repleto de equipes com indivíduos talentosos que compartilham uma visão durante algum tempo, mas que não conseguem aprender (SENGE, 2006).

Segundo Pinheiro e Reginato (2003), as empresas devem apoiar e incentivar as equipes, oferecendo-lhes os recursos necessários disponibilizando-lhes treinamentos que busquem novas tecnologias e ampliem o conhecimento humano. Existem várias formas de aprendizado em equipe. Pinheiro e Reginato (2003, p. 41) destacam que o objetivo do treinamento é "o desenvolvimento e o aperfeiçoamento individuais e da equipe". Isso faz com que a pessoa melhore em todos os sentidos, desenvolvendo suas habilidades, melhorando suas atitudes e aprimorando-se constantemente, aumentando a produtividade da empresa na qual está inserida.

Desde valores ensinados na família até regras estabelecidas no ambiente profissional, todas as faces dos valores humanos fazem-se presentes no trabalho; influenciando a característica coletiva na gestão de equipes. Cabe ressaltar que o coletivo que não pode ser pensado apenas como quantidade de pessoas e o que se produz nessa junção, mas também pela coletividade histórica, cultural, social, biológica que acompanha cada profissional (KASPARY; SEMINOTTI, 2012).

Reis et al. (2006) esclarecem que se está na era do conhecimento e o que realmente importa são as ideias; as pessoas são valorizadas pelas informações e conhecimentos que possuem. Reis et al. (2006, p. 47) lembram que "o que conta é o pensamento sistêmico que inclui a intuição e a imaginação junto à razão e à lógica".

As pessoas devem pensar não somente em si, mas no desenvolvimento de equipes (VERGARA, 2012). De acordo com Hunter (2004), o líder deve ser modelo para os demais membros, satisfazendo suas necessidades. Ele influencia as pessoas a trabalharem com entusiasmo em busca dos objetivos, visando ao bem comum e mantendo o equilíbrio da equipe.

Macêdo et al. (2006, p. 127) lembram que "o trabalho em equipe é um permanente processo de experimentação, troca e aprendizagem". Conforme os mesmos autores, para que a equipe funcione de uma melhor forma, torna-se necessário que defina objetivos claros, verifique prazos e recursos disponíveis, tenha boa comunicação, aceite as diferenças entre os membros, tenha capacidade de negociação, dê e receba feedback, seja otimista, tenha comportamento ético e seja flexível. Segundo Pinheiro e Reginato (2003, p. 33), "o retorno, também chamado pelo termo em inglês 'feedback', significa retroalimentação, resposta". Ainda de acordo com os autores, as pessoas, para se aprimorarem, devem dar e receber um retorno constante e sincero, com o objetivo de desenvolver a equipe, melhorando a comunicação e a produtividade na empresa. Sendo assim, se o feedback for dado sem o objetivo de julgar, indicando o(s) compartimento(s), respeitando as necessidades de quem o recebe, servirá para aumentar o grau de esclarecimento de todos. O retorno, a resposta na hora certa, evita o desperdício de tempo e proporciona clima mais harmônico. É por meio de mecanismos de retorno, de feedback, que se consegue participação ampla da equipe, garante-se ser ouvido e dando a certeza de que o que foi exatamente entendido era o que se queria transmitir (PINHEIRO; REGINATO, 2003).

As equipes de trabalho são essenciais para o progresso das organizações; para tanto, as empresas devem apoiar as equipes sempre que necessário. Assim sendo, estas têm condições de melhorar seu desempenho. Conforme Pinheiro e Reginato (2003), a comunicação, as ideias, a união, a aprendizagem contínua, o comprometimento, a liderança e o feedback são de grande importância para a busca de melhores resultados tanto para as equipes, quanto para a empresa na qual estão inseridas.

Vergara (2012) cita que o trabalho em equipe se torna um bom recurso para aprimorar habilidades e melhorar atitudes, sendo importante haver um comprometimento, que melhor ocorre quando o poder 
é compartilhado. Macêdo et al. (2006) destacam que a motivação tem relação com o comprometimento, o reconhecimento e as recompensas.

Pinheiro e Reginato (2003) salientam que cabe ao líder procurar saber o que gera motivação nas pessoas e nele mesmo. Cavalcanti et al. (2007) afirmam que o líder deve escolher uma direção rumo a um objetivo comum, deve também se autodesenvolver e se autoconhecer para desenvolver a confiança, tendo visão de futuro, mantendo o equilíbrio da equipe e motivando-a em busca do objetivo coletivo e da satisfação das necessidades de todos os seus integrantes.

\section{METODOLOGIA}

Este trabalho foi desenvolvido com base em pesquisa de campo, na qual foi utilizada, como método, a entrevista semiestruturada, caracterizando-se como exploratória e qualitativa. Segundo Gil (2007), a pesquisa semiestruturada é elaborada com perguntas sobre o tema abordado, deixando que o entrevistado responda livremente sem perder o foco.

Utilizou-se igualmente a pesquisa bibliográfica, buscando analisar livros e artigos que contemplassem o tema proposto. A entrevista foi aplicada aos líderes de duas Cooperativas de Garibaldi-RS, com perguntas direcionadas ao tema em estudo. As respostas foram gravadas com a autorização dos entrevistados (Consentimento Livre e Esclarecido); posteriormente, foram interpretadas e analisadas pela técnica de análise de Conteúdo.

Para a realização das entrevistas nas duas cooperativas, montou-se um roteiro de perguntas direcionadas aos princípios do cooperativismo, que versaram sobre os benefícios e as dificuldades do trabalho em equipe, a importância da cooperação, as características pessoais para um trabalho produtivo, a administração de conflitos, a valorização das ideias, o processo de aprendizagem e a liderança, tendo em vista a opinião dos líderes entrevistados. As empresas foram organizadas como empresa A e B para a análise das informações coletadas, no sentido de manter o nome original da empresa sob sigilo.

As informações coletadas foram analisadas por meio da análise de conteúdo. Barros e Lehfeld (2007) esclarecem que os resultados obtidos com as entrevistas devem ser classificados e categorizados. Segundo Bardin (2011), a análise por categorias é uma das técnicas da análise de conteúdo e trata da investigação de um tema; assim, são analisados criticamente para responder ao problema de pesquisa deste trabalho e demais questões pertinentes a ele. Os resultados são apresentados a seguir.

\section{RESULTADOS E DISCUSSÃO}

A apresentação dos resultados ocorrerá de acordo com as respostas obtidas nas duas cooperativas que fizeram parte da amostra. Na cidade onde foi realizado o estudo, existem quatro cooperativas formais, duas delas manifestaram interesse em participar da pesquisa. Portanto, a amostra caracteriza-se em ser por conveniência (facilidade de acesso às informações). Mais adiante, as respostas serão apresentadas e comentadas por assunto e cooperativa.

A cooperativa A atua no segmento vinícola, fundada em 22 de janeiro de 1931, possui 82 anos de existência. Conta com 350 associados e 120 funcionários. A cooperativa B atua no segmento comercial, sua fundação foi em 4 de abril de 1942, há 71 anos. Possui 1.167 associados e 167 funcionários. Como todas as cooperativas, as duas surgiram com a união de um grupo de pessoas que possuíam um objetivo em comum.

Ambas as cooperativas seguem os princípios do cooperativismo e visam beneficiar seus associados e clientes com produtos de qualidade e bom atendimento. Para que isso aconteça, contam com equipes de trabalho que têm em vista bons resultados para a empresa. Os líderes dessas equipes são as pessoas que fazem parte deste estudo.

A entrevistada 1 é coordenadora de controladoria, e a entrevistada 2 é coordenadora de Recursos Humanos, ambas da cooperativa A. Já a entrevistada 3 atua como chefe de caixa, e o entrevistado 4 possui o cargo gerencial, ambos trabalham na cooperativa B. Ao todo, foram ouvidos quatro gestores de cooperativismo. A escolha em entrevistar os gestores foi pelo fato de eles terem conhecimento amplo do que ocorre nas cooperativas.

A seguir serão apresentados alguns trechos e análises realizadas das entrevistas de acordo com os assuntos debatidos. 


\subsection{Princípios do cooperativismo}

Segundo a entrevistada 1, os princípios que mais se destacam na empresa são o compromisso com a comunidade, intercooperação, educação e formação. A entrevistada 2 cita os princípios de cooperação, sustentabilidade, transparência, comunidade, saúde, história, inovação e pessoas. A entrevistada 3 destaca a participação econômica, a intercooperação e o compromisso com a comunidade. O entrevistado 4 complementa com o princípio de educação e formação. Segundo Figueiredo (2009), os princípios do cooperativismo são adesão voluntária e livre, gestão democrática, participação econômica, autonomia e independência, educação e formação, intercooperação e compromisso com a comunidade. Com base nisso e nas respostas dos entrevistados, percebe-se que as cooperativas seguem os princípios do cooperativismo.

\subsection{Benefícios do trabalho em equipe}

"Através do trabalho em equipe, as pessoas se sentem motivadas, se comunicam melhor, se importam com a empresa, melhorando o relacionamento entre os integrantes" (entrevistada 1). "Cada setor depende do outro, e todos os setores devem fazer sua parte para que tudo funcione da melhor maneira, beneficiando o cliente" (entrevistada 3). $O$ entrevistado 4 complementa dizendo que o principal benefício para o cliente é o bom atendimento. Vergara (2012) destaca como benefícios do trabalho em equipe a rapidez da percepção e uso das informações, a produção de ideias mais ricas e o comprometimento. Tendo em vista o conhecimento passado pelo autor e as respostas dos entrevistados, percebe-se que, pelo comprometimento, as pessoas realmente sentem-se motivadas e preocupadas com o cliente.

\subsection{Dificuldades do trabalho em equipe}

A entrevistada 2 destaca a dificuldade de liderar pessoas com mais idade, devido à forma de pensamento ser diferente.

A entrevistada 3 comenta quea maior dificuldadeépela falta de comprometimento efalta de responsabilidade de colaboradores mais jovens. Já o entrevistado 4 enfatiza como dificuldade trabalhar com pessoas de idades muito diferentes. Conforme Reis et al. (2006), a resistência a mudanças é uma dificuldade nas empresas.

Macêdo et al. (2006) comentam que o fato de os integrantes da equipe possuírem idades diferentes dificulta o trabalho das equipes. Isso também foi visto nas duas empresas, pois a maior dificuldade citada pelos entrevistados é lidar com as diferenças de idade.

\subsection{A importância da cooperação}

"Designamos a cada colaborador suas funções e o papel do setor como um todo, assim todos têm o conhecimento de todas as funções e podem colaborar entre si" (entrevistada 2).

"Um setor depende do outro, e o cliente deve ser bem atendido em todos os setores. Um colega deve cooperar com o outro, para se obter um bom resultado" (entrevistada 3). O entrevistado 4 complementa, dizendo: "Unidos tentamos manter a organização da empresa".

No entendimento de Figueiredo (2009), a cooperação é importante, pois é por meio dela que as pessoas se unem e se ajudam mutuamente para o benefício de todos. Verifica-se, portanto, que os cooperados seguem o princípio de ajuda mútua, entendendo que isso contribui para que haja cooperação e, consequentemente, melhores resultados.

\subsection{Características pessoais para um trabalho produtivo}

Conforme a entrevistada 1, as características mais importantes são concentração, empenho, dinamismo, percepção e vontade de aprender. Já a entrevistada 2, ressalta a importância do comprometimento, da ética, de objetivos e o fato de saber trabalhar em equipe. 
A cooperação, a amizade, o envolvimento, o comprometimento e a responsabilidade são importantes, destaca a entrevistada 3. O entrevistado 4 complementa também citando a pontualidade, o respeito, a organização e o bom atendimento ao cliente.

Macêdo et al. (2006) consideram importantes as características: participação em ideias e resultados, adaptação a mudanças, comunicação, capacidade de observar e ouvir, aprendizado constante e criatividade. De acordo com as cooperativas pesquisadas, as características importantes são: concentração, empenho, dinamismo, percepção, vontade de aprender, comprometimento, ética, interesse, saber trabalhar em equipe, cooperação, amizade, envolvimento, responsabilidade, pontualidade, respeito, organização e bom atendimento. Sendo a característica mais citada pelos entrevistados o comprometimento.

\subsection{Administração de conflitos}

Segundo a entrevistada 1, a cooperativa possuía alguns conflitos no passado relativamente à insatisfação de funcionários que comparavam diferenças de salário, mas hoje isso já não existe. Ressalta que administrar conflitos não é tarefa fácil, pois cada pessoa pensa de maneira diferente. Já a entrevistada 2 comenta que a direção é aberta, administra os conflitos conversando com os colaboradores.

A entrevistada 3 diz que existem conflitos e que estes são resolvidos da melhor maneira para melhorar o ambiente de trabalho. "Os problemas de casa são levados ao trabalho e vice-versa”, isso é resolvido conversando com o colaborador (entrevistado 4).

Segundo Macêdo et al. (2006), os conflitos surgem quando os membros da equipe pensam diferente, quando há falhas na comunicação ou excesso de normas. Já, conforme Pinheiro e Reginato (2003), os conflitos são necessários, incentivam o crescimento da empresa e a criatividade das pessoas. Podem ser administrados com reuniões e negociações para a solução do problema. Ambas as empresas veem na comunicação com as partes envolvidas a solução desses conflitos.

\subsection{A valorização das ideias}

"No livro "La Nostra Cooperativa”, escrito por Cassius André Fanti, os funcionários colaboraram com ideias, mas no meu setor não existe esse tipo de premiação". Esta foi a afirmativa da entrevistada 1, enaltecendo a falta de incentivo para a geração de ideias. Já a entrevistada 2 diz que são realizadas reuniões entre os setores e a presidência, nas quais os colaboradores dão ideias de melhorias. E complementa "não queremos que seja recompensada uma ideia e sim que seja parte do nosso dia a dia ter ideias".

Existe a escolha de uma frase para o evento direcionado à Comissão Interna de Prevenção de Acidentes (CIP), em que a equipe vencedora é presenteada com um valor em dinheiro.

Na concepção de Vergara (2012), a produção de ideias mais ricas é uma vantagem do trabalho em equipe, pois se baseia na visão diferente de cada integrante. Conforme as entrevistas realizadas, percebe-se que não existe uma política de ideias nas cooperativas, mas sim algumas situações em que os colaboradores são motivados a colaborar com ideias.

\subsection{Processo de aprendizagem trabalhador/cooperador}

"Não existe hoje um programa de integração, somente o encontro nas assembleias", queixa-se a entrevistada 1. A entrevistada 2 diz que existe uma integração entre funcionários e afirma que funcionários e associados encontram-se somente nas assembleias.

Para a entrevistada 3, "os trabalhadores e cooperados conversam no dia a dia, quando o cooperado vai até a empresa e nas assembleias". Conforme Figueiredo (2009), o ensino cooperativista melhora a qualidade de vida e o desenvolvimento social das pessoas. Com base nisso, perguntou-se às cooperativas referentes aos processos de aprendizagem na organização e, analisando-se as respostas, percebeu-se que em ambas as cooperativas não existe o processo de aprendizagem entre trabalhador e cooperador. 


\subsection{Liderança}

"Alguns líderes foram titulados líderes, mas ainda não são. Faz dez anos que estou na cooperativa e sempre fui operacional, a pessoa que se destaca no operacional acaba sendo uma cabeça pensante", são as palavras da entrevistada 1, que complementa dizendo que a liderança ainda é um fator que deve ser desenvolvido na empresa e para as pessoas que estão há a mais tempo ali é difícil a aceitação de líderes. O líder deve ser exemplo, saber se comunicar e entender a equipe.

Na opinião da entrevistada 2 "Para os colaboradores, o líder deve entender, conversar e compreender o que se passa além da produção". Resumidamente, o líder deve passar segurança. Os entrevistados 3 e 4 comentam que o papel do líder é entender o liderado para encontrar maneiras de ajudá-lo, melhorando, assim, o ambiente de trabalho.

Bergamini (2009) ressalta que o líder deve auxiliar sua equipe oferecendo fatores que satisfaçam seus liderados e que esses fatores façam sentido para eles. Este item não consta no roteiro de entrevista, mas percebeu-se, durante as entrevistas, a importância da liderança no trabalho em equipe, pelos comentários dos entrevistados. Com isso, verifica-se que o líder deve auxiliar e motivar sua equipe para obterem bons resultados para a organização.

\section{CONSIDERAÇÕES FINAIS}

O trabalho em equipe é um dos fundamentos do cooperativismo (FIGUEIREDO, 2009). Por esse motivo, estudou-se primeiramente o histórico do cooperativismo. Macêdo et al. (2006) alertam dizendo que o trabalho em equipe se dá entre pessoas que se unem em prol de um objetivo em comum; então, pode-se perceber que o trabalho em equipe depende da cooperação entre os membros. Diante disso, realizou-se uma pesquisa de campo em cooperativas de Garibaldi, com os objetivos de conhecer o histórico de desenvolvimento das cooperativas no estado do Rio Grande do Sul, dimensionar os benefícios e as dificuldades do trabalho em equipe, e conhecer os aspectos relacionados ao trabalho de líderes nas organizações cooperativadas, com o intuito de chegar ao objetivo principal de verificar se as cooperativas de Garibaldi seguem os princípios do cooperativismo.

Com a pesquisa bibliográfica, alcançou-se o objetivo de conhecer o histórico de desenvolvimento das cooperativas no Rio Grande do Sul. Por meio da pesquisa, entendeu-se o sentido da cooperação e da união das pessoas, comparando o passado com o presente, compreendendo as dificuldades enfrentadas ao longo dos anos. Figueiredo (2009) apresentou os princípios do cooperativismo, os quais auxiliaram o direcionamento deste trabalho. Percebeu-se que o ensino cooperativista, com os seus valores e virtudes, pode propiciar benefícios ao trabalho em equipe.

Por intermédio das entrevistas realizadas com os líderes das cooperativas, identificou-se que as cooperativas em estudo seguem os princípios do cooperativismo e verificou-se, ainda, que os benefícios do trabalho em equipe mais citados são a motivação, a comunicação e a cooperação para o bom relacionamento entre colaboradores e para o bom atendimento ao cliente e ao cooperado; como consequência, são melhores os resultados para a organização. Em termos de contribuição cientifica, percebeu-se a existência de dez benefícios advindos do trabalho em equipe: melhor percepção e uso das informações, a produção de ideias mais ricas, o comprometimento, a motivação, o desenvolvimento da liderança, a boa comunicação, o aprendizado constante, o crescimento pessoal, o bom atendimento ao cliente e a união entre os membros da equipe.

Em relação às dificuldades para o trabalho em equipe nas cooperativas, verificou-se a existência de conflitos de personalidade e o fato de as diferenças de idades entre os trabalhadores serem igualmente uma barreira. Como contribuição científica, evidenciaram-se seis dificuldades do trabalho em equipe: a cultura ocidental, a cultura organizacional, os conflitos de personalidades, as falhas na comunicação, a falta de motivação e as diferenças de idade entre os membros da equipe.

Viu-se, ainda, uma postura adequada dos líderes. De acordo com os cooperados, o líder deve ser um modelo para a equipe, administrar conflitos, transmitir segurança aos liderados e saber se comunicar, sendo estas indicações também apontadas na literatura. 
Percebeu-se, também, neste estudo, que uma boa comunicação resolve os conflitos que surgem nas cooperativas. Acredita-se que o fator que deveria ser mais presente é a política de ideias, pois incentiva a criatividade e pode melhorar o trabalho. $O$ processo de aprendizagem aliado à liderança é de grande importância, pois o líder tem o papel de orientar e motivar a equipe. Diante das considerações anteriores, pode-se indicar que o trabalho em equipe é essencial para o bom funcionamento das cooperativas, resultando em um melhor desempenho dos integrantes desta, no desenvolvimento de talentos, na descoberta de novos líderes, nos benefícios aos cooperados e clientes das cooperativas e nos melhores resultados para a organização.

\title{
THE PRINCIPLES OF COOPERATIVES AND THE TEAMWORK IN COOPERATIVES OF GARIBALDI-RS
}

\begin{abstract}
The cooperative principles and teamwork are of great importance in cooperative organizations. Due to the relevance of this theme, this research has as main objective to verify if the the cooperatives in Garibaldi follow the principles of the cooperative system. To achieve this goal, we studied the historical development of cooperatives in Rio Grande do Sul State, tried to identify the benefits and difficulties related to teamwork in cooperatives and to analyse the issues related to the work of leaders in cooperative organizations. The fieldwork took place in Garibaldi cooperatives, and to this end, we conducted a qualitative study where information was obtained from the leaders of the cooperatives. The research technique used was the semi-structured interview, using an interview guide, and literature review on the topic. After interpretation and analysis of the data collected, we observed that the cooperatives in study follow the principles of the cooperative system and that teamwork is very important for them because it improves the performance of team members, benefits cooperative members and customers, and also adds to the organization's results.
\end{abstract}

Keywords: Cooperativism. Team work. Integration.

\section{REFERÊNCIAS}

BARDIN, L. Análise de conteúdo. Lisboa: Edições 70, 2011.

BARROS, Aidil Jesus da Silveira; LEHFELD, Neide Aparecida de Souza. Fundamentos de metodologia científica. São Paulo: Pearson Prentice Hall, 2007.

BEJARANO, Viviane Carvalho; PILATTI, Luiz Alberto. Elementos Externos Essenciais à Implementação de Equipes: estudo de caso. Revista Administração, São Paulo, v. 43, n. 1, p. 17-29, jan./mar. 2008.

BERGAMINI, Cecilia Whitaker. O líder eficaz. São Paulo: Atlas, 2009.

CAVALCANTI, Vera Lucia et al. Liderança e motivação. Rio de Janeiro: FGV, 2007.

COOPERATIVA DOS PROFISSIONAIS DE EDUCAÇÃO DO ESTADO DE SÃO PAULO (COOPESP). História do

Cooperativismo. Disponível em: <http://www.coopesp.org.br/cooperativismo>. Acesso em: 14 dez. 2012.

FIGUEIREDO, Nilsa Terezinha Capiem de. Cooperativas Sociais: Alternativa para Inserção. Porto Alegre: Evangraf, 2009.

GIL, Antonio Carlos. Métodos e Técnicas de Pesquisa Social. São Paulo: Atlas, 2007. 
HUNTER, James C. O Monge e o Executivo: Uma História sobre a Essência da Liderança. Rio de Janeiro: Sextante, 2004.

KASPARY, Magda Capellão; SEMINOTTI, Nedio Antonio. Os Processos Grupais e a Gestão de Equipes no Trabalho Contemporâneo: Compreensões a partir do Pensamento Complexo. Revista Administração Mackenzie, São Paulo, v. 13, n. 2, p. 15-43, mar./abr. 2012.

LAGO, Adriano; SILVA, Tania Nunes da. Fatores condicionantes do desenvolvimento de relacionamentos intercooperativos no cooperativismo agropecuário. Porto Alegre, RS: SESCOOP, 2009.

MACÊDO, Ivanildo Isaias de et al. Aspectos comportamentais da gestão de pessoas. Rio de Janeiro: FGV, 2006.

ORGANIZAÇÃO DAS COOPERATIVAS BRASILEIRAS (OCB). Panorama do Cooperativismo Brasileiro.

Disponível em: <http://www.ocb.org.br/site/agencia_noticias/noticias_detalhes.asp?CodNoticia=13837>. Acesso em: 2 set. 2015.

OLIVEIRA, Aline Carrijo de. Língua Portuguesa. Blumenau: Vale das Letras, 2011.

PINHEIRO, Rosane Fraga; REGINATO, Antônio Pulo. Equipes Campeãs: Desenvolvendo o Potencial das Equipes. Porto Alegre, RS: SEBRAE, 2003.

REIS, Ana Maria Viegas et al. Desenvolvimento de equipes. Rio de Janeiro: FGV, 2006.

SCHNEIDER, Cristina Seibert. Cooperativa Santa Clara: 100 anos de história. Porto Alegre, RS: SESCOOP, 2012.

SENGE, Peter M. A quinta disciplina: Arte e prática da organização que aprende. Rio de Janeiro: Best Seller, 2006.

SINGER, P. A recente ressurreição da economia solidária no Brasil. In: SANTOS, B. S. (Org.). Produzir para viver: os caminhos da produção não capitalista. Rio de Janeiro: Civilização Brasileira, 2002. cap. 1.

SIMON, Camilo. A Revolução Silenciosa: A saga da eletrificação rural cooperativada do RS. Porto Alegre, RS: SESCOOP, 2011.

VERGARA, Sylvia Constant. Gestão de Pessoas. São Paulo: Atlas, 2012.

VIANA, Ediane Muller. Cooperativa de trabalho Educacional: História, Princípios, Governança e Legalidade. Porto Alegre, RS: SESCOOP, 2013.

WILLWOCK, Luís Humberto de Mello et al. Os Desafios da Intercooperação em um Mercado Comum em Formação: Um estudo preliminar de centrais agropecuárias na região sul. Disponível em: <http://cdn.fee. tche.br/jornadas/2/E13-01.pdf>. Acesso em: 10 out. 2014.

ZENI, AngeloElocir. Trabalho Cooperativo: À Luz da Legislação e Doutrina Brasileira e Espanhola. Porto Alegre, RS: SESCOOP, 2008. 